\title{
Atuação profissional dos egressos do programa de educação tutorial de um curso de enfermagem
}

\author{
Professional performance of egresses from the \\ tutorial education program of a nursing course
}

\author{
Thaynara Ferreira Lopes ${ }^{1}$ \\ Beatriz Viana da Silva ${ }^{2}$ (1) \\ Luana Sousa de Carvalho 3 (1) \\ Suellen Silva $\mathrm{Vaz}^{4}$ (1) \\ Jamile Mineu Pereira 5 (1)
}

Rhanna Emanuela Fontenele Lima de Carvalho ${ }^{6}$ (1)

${ }^{1}$ Autora para correspondência. Universidade Estadual do Ceará (Fortaleza). Ceará, Brasil. thaynaralopes.13@hotmail.com 2-6Universidade Estadual do Ceará (Fortaleza). Ceará, Brasil. b_viana95@hotmail.com, luanasousa741@gmail.com, suh_vaz@hotmail.com, jam.mineu@gmail.com, rhannalima@gmail.com

RESUMO | OBJETIVO: conhecer as contribuições do Programa de Educação Tutorial (PET) para a atuação profissional dos egressos do curso graduação em enfermagem de uma Universidade do Nordeste do Brasil. MÉTODO E MATERIAIS: trata-se de uma pesquisa descritiva com abordagem quantitativa e qualitativa. A coleta de dados ocorreu em 2017 por meio de questionário com perguntas sobre as habilidades desenvolvidas enquanto bolsistas e as contribuições na carreira profissional do egresso. Todos os 84 ex-bolsistas foram convidados a participar, dos quais 47 responderam ao questionário. RESULTADOS: 75,5\% dos egressos desse programa conseguem rápida inserção no mercado de trabalho com perspectivas de reingresso na universidade por meio dos cursos de pós-graduação. Em relação às contribuições do programa na carreira profissional, afirmaram que as competências desenvolvidas facilitaram a solidificação do perfil profissional desejado. Revelaram que o programa foi importante para a carreira profissional, e que também contribuiu no desenvolvimento pessoal. Ademais, $51 \%$ relataram que o trabalho em equipe e relacionamento interpessoal foram as competências que mais colaboraram na vida profissional. CONSIDERAÇÕES FINAIS: foi possível perceber a importância da atuação do programa na formação acadêmica e profissional dos estudantes do curso de enfermagem, a partir do desenvolvimento de habilidades realizadas no grupo.

DESCRITORES: Enfermagem. Capacitação profissional. Desempenho profissional.

\begin{abstract}
OBJECTIVE: to know the contributions of the Tutorial Education Program (PET) to the professional performance of graduates of the undergraduate nursing course at a University in the Northeast of Brazil. METHOD AND MATERIALS: this is a research with a quantitative and qualitative approach. Data collection took place in 2017 through a questionnaire with questions about the skills developed as fellows and the contributions of the program in the graduate's career. All 84 alumni were invited to participate, of which 47 responded to the questionnaire. RESULTS: $75.5 \%$ of the graduates of this program achieve rapid insertion in the job market with prospects of re-entering the university through postgraduate courses. Regarding the contributions of the program in the professional career, they stated that the skills developed facilitated the solidification of the desired professional profile. When asked if the program contributed to their professional career, they replied that it was important in this regard, but also contributed to personal development. In addition, 51\% reported that teamwork and interpersonal relationships were the skills that contributed most to professional life. FINAL CONSIDERATIONS: it was possible to perceive the importance of the program's performance in the academic and professional training of nursing students, based on the development of skills performed in the group.
\end{abstract}

KEYWORDS: Nursing. Professional training. Professional performance. 


\section{Introdução}

A graduação é um momento importante para a formação do conhecimento e da autonomia pessoal e profissional dos estudantes, pois é durante esse período que o formando é estimulado a dialogar com os diferentes saberes disciplinares e a integrá-los com o intuito de contribuir para o desenvolvimento social.

Diante disso, o Programa de Educação Tutorial (PET), vinculado ao Ministério da Educação e tendo como base o tripé universitário, ensino, pesquisa e extensão, envolve os integrantes em um processo de formação integral voltado para uma compreensão mais abrangente do processo ensino-aprendizagem. $\mathrm{O}$ programa valoriza atividades interdisciplinares, atuação coletiva e criatividade no ambiente acadêmico, buscando integrar a formação acadêmica com a futura profissão dos seus membros ${ }^{1}$.

É importante enfatizar que a proposta trazida pelo PET à comunidade universitária estabelece um divisor importante entre ele e qualquer outro programa de formação acadêmica: a ideia de enfatizar o ensino, a pesquisa e a extensão, pilares básicos que sustentam o saber universitário, consubstanciada pelo aspecto político adquirido ao longo dos anos pelo programa e pela ideia de tutoria de pequenos grupos por docentes capacitados para a função definem os ingredientes básicos para a formação de líderes².

Com esse propósito, o PET tem como objetivo geral melhorar o processo de ensino aprendizagem junto aos cursos de graduação, tendo em vista que cada curso atua de forma independente, mas sempre dialogando de maneira interprofissional, ampliando as perspectivas de qualificação e formação dos acadêmicos. Nesse sentido, apresenta-se como um importante instrumento pedagógico por propiciar aos seus componentes um aprendizado voltado para o desenvolvimento de competências relacionadas à criatividade, versatilidade, flexibilidade, capacidade de relacionar-se, comunicar-se e resolver problemas ${ }^{3}$.

No curso de enfermagem, o programa promove uma vivência de trabalho em grupo e atitudes de liderança que são essenciais para os futuros profissionais da saúde, pois, nesse ambiente, é necessário manter uma convivência harmoniosa entre os integrantes da equipe. Além disso, a perspectiva de realizar atividades de ensino, pesquisa e extensão, estimula o bolsista a um olhar mais crítico e reflexivo sobre a profissão, o que pode contribuir para o seu desempenho profissional futuro?

Dessa forma, a Educação Tutorial configura-se como uma referência de desenvolvimento profissional em Enfermagem baseado na situação social e em concordância com o Sistema Único de Saúde (SUS), especialmente no que diz respeito as orientações no ensino, aprendizagem e atuação4.

Nesse cenário, é necessário destacar a escassez de publicações, pesquisas e dados que reforcem a importância da atuação desses programas no contexto da educação no país, como um programa que ajuda a estimular o estudante para uma futura carreira profissional. Diante disso, justifica-se a necessidade de mais estudos e pesquisas que avaliem o impacto, a atuação e o perfil de estudantes que passam pelo PET e entram no mercado de trabalho, pois seria um estímulo a maior divulgação e criação de mais grupos como estes nas universidades.

Portanto, elaborou-se a seguinte questão de pesquisa: como o Programa de Educação Tutorial (PET) contribui para a formação profissional dos seus egressos? Portanto, essa pesquisa teve como objetivo conhecer as contribuições do Programa de Educação Tutorial (PET) para a atuação profissional dos egressos do curso graduação em enfermagem de uma Universidade do Nordeste do Brasil.

\section{Método}

Trata-se de uma pesquisa descritiva com abordagem quantitativa e qualitativa. A pesquisa foi realizada no primeiro semestre de 2017 com 47 egressos que integraram o PET do curso de enfermagem da Universidade Estadual do Ceará desde a formação em 1994 até 2015.

Para participar da pesquisa, os profissionais deveriam atender o seguinte critério de inclusão: ter sido bolsista oficial ou voluntário do PET do curso de enfermagem nos últimos 21 anos. Os critérios de exclusão: não conseguir contato com o egresso, através de e-mail, telefone, rede social ou não encontrar o cadastro do profissional na plataforma Lattes. 
O convite para participar do estudo se deu a partir da lista de egressos contida nos livros de ata fornecida pela Instituição de Ensino Superior (IES). Dessa forma, foram enviadas cartas-convites por e-mail, redes sociais e pelo e-mail vinculado ao Currículo Lattes. Todos os 84 ex-bolsistas foram convidados a participar da pesquisa, destes 47 responderam ao questionário.

O instrumento para coleta de dados foi produzido utilizando uma ferramenta do Google Docs e enviado por e-mail aos participantes. O referido instrumento continha 12 questões fechadas relacionadas ao perfil sociodemográfico, a qualificação e atuação profissional e quatro questões abertas, com perguntas sobre o alcance dos objetivos do programa, habilidades desenvolvidas enquanto bolsista, contribuições do programa na carreira do egresso e continuidade em atividade de pesquisa, ensino e extensão após conclusão do curso.

Os dados foram inseridos no Microsoft Excel para conformação do banco de dados e a análise ocorreu, para os dados quantitativos, por meio da utilização de técnicas de estatística descritiva.

Para a análise qualitativa foram seguidas as três etapas de análise de conteúdo citadas por Campos $^{5}$. A primeira etapa refere-se a fase de pré-exploração do material ou de leituras flutuantes das respostas das quatro questões abertas. Nessa etapa, as respostas dos participantes da pesquisa foram lidas pelos pesquisadores, sendo cinco deles graduandos e um doutor, no intuito de apreender e organizar de forma não estruturada aspectos importantes para as próximas fases da análise. A segunda fase foi realizada a seleção das unidades de análise (ou unidades de significados). Nessa etapa, realizou-se o recorte de frases e parágrafos com significados semelhantes, de acordo com cada questão. Por fim, a terceira etapa foi realizada a categorização das respostas, evidenciando quatro categorias: o alcance dos objetivos do programa, as habilidades desenvolvidas durante o período como bolsista do programa, as contribuições do PET para a carreira profissional e as atividades desenvolvidas pelo egresso sobre ensino, pesquisa ou extensão.

Para garantir o sigilo das informações, as falas dos egressos foram identificadas no texto com a letra "E" e seus respectivos códigos. A pesquisa foi submetida ao Comitê de Ética em Pesquisa da Universidade Estadual do Ceará, obtendo o parecer número 2.041.763, CAAE 66645717.6.0000.5534 de 02/05/2017 e seguiu todas as orientações da Resolução 466/12 do Conselho Nacional de Saúde ${ }^{6}$.

\section{Resultados}

Em relação ao perfil dos ex-bolsistas, 43 (90\%) foram do sexo feminino e passaram em média, 38 meses como bolsista do programa. Quanto à qualificação, 45 (94\%) possuem pós-graduação, sendo oito doutores $(17,7 \%)$, três mestres $(6,6 \%)$ e 24 especialistas $(53,3 \%)$. As especialidades foram variadas, dentre elas, cardiologia, obstetrícia, terapia intensiva e saúde coletiva.

Logo após a graduação (menos de seis meses), 36 $(75,5 \%)$ estavam empregados, 30 (63,8\%) em instituições públicos, $10(21,3 \%)$ em instituições privadas e 7 $(12,7 \%)$ em ambas, com dedicação de 31 a 40 horas semanais $24(49 \%)$.

A faixa de remuneração dos egressos apresentou grande variação, desde o valor da bolsa de mestrado e/ou residência até mais de dez salários mínimos 16 (32,7\%).

Quanto às respostas das questões abertas, o primeiro item "Durante o período em que você foi bolsista, você considera que o programa alcançou o tripé (ensino, pesquisa e extensão)?", a maioria dos egressos 32 (68\%) respondeu "sim", afirmando que o programa atingiu o objetivo de abordar o tripé universitário. $\mathrm{O}$ ensino foi ressaltado como o aspecto mais trabalhado no programa. Dentre as atividades, as mais comentadas foram: monitorias, palestras, rodas de conversa, cursos, oficinas e eventos. No que se refere às atividades de extensão, as mais citadas foram as visitas às enfermarias pediátricas em hospitais públicos, oficinas e grupos de educação em saúde para crianças, mulheres e idosos.

No entanto, vale salientar que oito egressos destacaram a dificuldade de articular os três eixos (ensino, pesquisa e extensão). A pesquisa e a extensão estavam sempre atreladas, porém, havia dificuldades em articular o ensino com esses dois eixos. Além disso, foi comentado pelos entrevistados, sobre à sobrecarga e a dificuldade de aliar as atividades do programa com as responsabilidades da graduação. É possível constatar esses aspectos nos seguintes depoimentos: 
(...)mas penso que o programa é completo e nos possibilita experienciar ações no âmbito do ensino, ações educativas, pesquisas individuais e coletivas entre outras. (E43)

(...)nossas produções se limitaram a apresentações em eventos científicos. Poderíamos ter avançado para publicações científicas em periódicos. Precisei ingressar em grupo de pesquisa da Universidade para desenvolver melhor essa área e pleitear uma vaga no mestrado na época. (E37)

Quanto à segunda questão "Quais habilidades você desenvolveu durante o seu período de bolsista do programa?". Sendo as habilidades mais mencionadas o trabalho em equipe 26 (55\%), comunicação e oratória 23 (49\%), organização, planejamento e gerenciamento 11 (23\%), organização de eventos 10 (21\%), liderança 9 (19\%), criatividade $5(11 \%)$, protagonismo e autonomia 4 (9\%), além de interesse por cultura e política.

Sobre as contribuições do PET na carreira profissional, foi relatado que o trabalho em grupo, a oratória e a postura profissional incentivada durante o desenvolvimento das atividades do programa, possibilitaram segurança nas tomadas de decisões profissionais. De acordo com os participantes da pesquisa, essas competências facilitaram a consolidação do perfil profissional desejado, proporcionando atitudes de liderança, responsabilidade e organização. Sendo explicitada a importância e a colaboração do programa:

O Programa de Educação Tutorial, como um grupo, me ajudou saber como trabalhar em equipe e poder identificar as habilidades de seus integrantes, para assim usá-las da melhor maneira possível. Isso faz que você em seu ambiente de trabalho como líder da equipe de enfermagem, possa saber reconhecer em seus membros suas habilidades e usar para prestar uma melhor assistência ao paciente. (E40)

O terceiro item do questionário perguntava "Como o programa contribuiu para a carreira profissional?". Os respondentes descreveram que o mesmo foi importante não somente para a vida profissional, mas também no desenvolvimento pessoal. Para 24 (51\%) dos egressos, o trabalho em equipe e relacionamento interpessoal foram as competências adquiridas que mais contribuíram com a carreira profissional.

Por fim, em relação a quarta e última questão "No momento, você desenvolve alguma atividade de ensino, pesquisa ou extensão?", foram obtidas 34 (81\%) respostas "Sim", afirmando que os egressos continuam desenvolvendo alguma dessas atividades. O ensino foi a atividade mais desenvolvida, seguida pela pesquisa, principalmente relacionada à inserção nos programas de pós-graduação latu sensu. Também foi possível notar que há egressos que desenvolvem as três atividades (ensino, pesquisa e extensão), como mencionado abaixo:

Desenvolvo as três. Sou docente de um curso superior de enfermagem. Como fui bolsista do programa, aprendi sobre a necessidade de articular as três coisas em todas as atividades que planejo. Nem sempre isso é possivel, mas tento porque sei que é importante para o desenvolvimento dos alunos. (E33)

Ademais, 18 (40\%) relataram que as atividades alicerçadas no tripé proporcionaram uma visualização de um início à docência ou na área de pesquisa. São notórias estas informações no depoimento que segue:

No tripé, o quesito ensino era o mais desenvolvido. Planejávamos atividades diversificadas relacionadas a isso, sendo assim, me foi oportunizado conhecer muitos aspectos do ensinar. Sou docente e percebo que minha habilidade com comunicação foi bastante estimulada na época em que fui bolsista do programa. (E32)

\section{Discussão}

Em 2008, o Ministério da Educação (MEC) iniciou uma pesquisa sobre o perfil dos ex-bolsistas do programa com o objetivo de investigar se o PET tem cumprido seu papel no sentido de influenciar a inserção e o desenvolvimento acadêmico, profissional e pessoal dos seus egressos. No entanto, não foram divulgados os resultados dessa pesquisa, e o que tem se observado são algumas iniciativas isoladas de grupos interessados em conhecer essa realidade ${ }^{?}$.

Pôde-se encontrar, pelos resultados deste estudo, o predomínio do sexo feminino, sendo que essa maioria na enfermagem é histórica, no entanto tem-se observado um aumento do contingente masculino em sua composição .

Além disso, apesar dos poucos estudos sobre o perfil de egressos do programa e da diversidade de métodos identificados nesses estudos, observou-se que os resultados desta pesquisa são semelhantes aos da- 
dos apresentados no estudo dos egressos do programa do curso de Física da Universidade Federal do Rio Grande do Norte (UFRN), o qual também identificou que, em sua maioria, os egressos retornaram à instituição na academia? .

Diante do mercado de trabalho dinâmico e competitivo, as habilidades desenvolvidas dentro do programa são relevantes, em especial na busca pelo primeiro emprego, como mostram os resultados referentes ao tempo de inserção dos egressos no mercado de trabalho.

Um outro ponto a evidenciar é que a faixa de remuneração dos egressos apresentou grande variação, desde o valor da bolsa de mestrado até mais de dez salários mínimos. Resultados equivalentes foram identificados em uma pesquisa referente à inserção dos egressos no mercado de trabalho, na qual $55 \%$ dos egressos dos grupos do grupo PET estudados levaram menos de seis meses para ingressar no primeiro emprego, 54,1\% em instituições públicas e cursaram ou estavam cursando pós-graduação $(79,9 \%)^{10}$.

A dificuldade relatada para realizar as atividades do tripé-universitário durante a graduação de enfermagem ocorre devido ao pouco tempo disponível para a execução de atividades extracurriculares durante o curso. Diante disso, ressalta-se a importância de um currículo integrado, que atenda às demandas do perfil profissional desejado, além de formar um aluno crítico, politicamente ativo e capaz de reconhecer situações-problema ${ }^{11}$.

Além disso, a Secretaria de Educação Superior (SESU) orienta quanto aos objetivos e a importância da implementação das atividades de ensino, pesquisa e extensão no planejamento anual dos grupos. Com isso, tem-se o compromisso com a formação acadêmica de qualidade para os integrantes do programa e com toda a graduação, referente a uma melhor preparação dos alunos para atuar no seu futuro campo profissional e ao desenvolvimento de novas práticas e experiências pedagógicas no curso de graduação ${ }^{12}$.

De acordo com as Diretrizes Curriculares Nacionais do Curso de Graduação em Enfermagem são habilidades essenciais no exercício da profissão a liderança, organização, planejamento, supervisão e avaliação das atividades da equipe de enfermagem, uma vez que cabe a este profissional essas funções.
Outro aspecto fundamental é que as habilidades desenvolvidas no programa estão relacionadas à atuação do profissional no ambiente de trabalho no que diz respeito a coordenação e otimização do trabalho, comunicação efetiva com a equipe multidisciplinar e incentivo ao raciocínio clínico ${ }^{13}$.

Para o enfermeiro, essas habilidades são essenciais, visto que ele é um dos integrantes da equipe multiprofissional que presta assistência ao paciente e que tem a comunicação, o planejamento e a autonomia como pressupostos para um cuidado de qualidade ${ }^{3}$.

O perfil do bolsista do PET é aquele que se destaca por apresentar habilidades, tais como capacidade de trabalhar em equipe, autonomia, tomada de decisão, proatividade, espírito de liderança e iniciativa, contribuindo para a formação de um profissional crítico e atuante, orientado pela cidadania e pela função social da educação superior, bem como, para o crescimento individual e interpessoal, formando um profissional com visão ética e humanista $\$$.14.

Nesse contexto, a regulamentação do PET, que foi instituída pela Lei 11.180/2005 e regulamentada pelas Portarias $n^{\circ} 3.385 / 2005, n^{\circ} 1.632 / 2006$ e $n^{\circ}$ 1.046/2007, que consta no manual de orientações básicas, estabelece como o programa deve funcionar, qual a constituição administrativa e acadêmica, além de determinar as normas e a periodicidade do processo de avaliação nacional dos grupos. Após cinco anos desde a sua instituição, a regulamentação da Portaria n 976/2010 trouxe inovações para a estrutura do programa como a flexibilização e dinamização da estrutura dos grupos, a união do PET com o Conexões de Saberes, a determinação de tempo máximo de exercício da tutoria, a aproximação com a estrutura acadêmica da universidade e a definição de estruturas internas de gestão do programa ${ }^{7}$.

Desse modo, o programa passa por atualizações com a finalidade de inovar e integrar mais estudantes e evidencia-se como um grupo relevante para que as habilidades individuais e coletivas sejam potencializadas e desenvolvidas e os obstáculos do processo ensino-aprendizado sejam superados. Esse cenário reflete no ambiente de trabalho dos egressos, tendo o enfermeiro, como chefe da equipe, a função de reconhecer as habilidades da equipe para prestar uma assistência qualificada ${ }^{15}$. 
O bolsista do programa, desde o início, é incentivado a implementar as atividades de pesquisa, ensino e extensão, em forma de projetos, estimulando o planejamento coletivo das ações com vistas a atingir um ou mais objetivos. Os projetos do grupo servem para integrar os conhecimentos, por vezes fragmentados durante a graduação. Tais experiências contribuem para o desenvolvimento profissional e oferecem oportunidades enriquecedoras para a vida acadêmica do bolsista ${ }^{16}$.

Esses resultados vão ao encontro com os objetivos preconizados pelo $\mathrm{PET}$, os quais ressaltam o desenvolvimento de competências e habilidades voltadas ao trabalho coletivo integrado do curso com a comunidade, com a finalidade de obter habilidades sociais e despertar o espírito de investigação ${ }^{12}$.

Diante disso, pesquisas afirmam que quanto mais cedo o aluno de graduação iniciar em atividades de ensino, pesquisa e extensão durante o curso, maiores são as chances de ingressarem na universidade em cursos de pós-graduação ${ }^{16}$.

Evidencia-se com esses resultados a importância do programa na formação profissional para a atualidade, visto que os objetivos desse programa buscam oferecer uma formação acadêmica de excelência aos alunos de graduação, além de incentivar o ingresso na pós-graduação, estimular a melhoria da qualidade de ensino de graduação através do desenvolvimento de novas práticas e experiências pedagógicas. Além do mais, um dos objetivos do programa, segundo o MEC, é fornecer uma formação acadêmica de excelente nível, formar um profissional crítico e atuante, orientado pela cidadania e pela função social da educação superior, por meio do desenvolvimento de ações coletivas e capacidade de trabalho em grupo ${ }^{12,17}$.

Tais objetivos se alinham à formação do enfermeiro ao proporcionar a experiência de trabalho colaborativo e interprofissional e atitudes de liderança que são imprescindíveis para o mercado de trabalho, principalmente, quando envolve os profissionais da saúde, sendo necessária a manutenção de uma boa convivência entre os integrantes da equipe, propiciando a segurança do paciente ${ }^{18}$.

Assim, os resultados dessa pesquisa mostraram que o programa tem atingido o seu objetivo nesse grupo quanto à qualificação, preparação e atualização do aluno para o mercado de trabalho, proporcionando uma formação crítica, ativa e criativa.

\section{Considerações finais}

O estudo evidenciou a importância do programa na formação do grupo de egressos por meio das atividades de ensino, pesquisa e extensão, uma vez que oportunizou o desenvolvimento de habilidades de comunicação, trabalho em equipe, relação interpessoal e criatividade, essenciais para a formação do enfermeiro. Além disso, mostrou que uma grande parcela dos egressos conseguiu inserção no mercado de trabalho com menos de seis meses do término do curso e ingressaram em cursos da pós-graduação.

O estudo demonstra as contribuições do programa não apenas na formação profissional, mas também na construção de cidadãos críticos e conscientes com a realidade social. O que se deve a experiência dos bolsistas em um programa que preza pela proximidade com a comunidade, discussão e contribuição para com os mesmos.

A fragilidade deste estudo se dá, essencialmente, pela lacuna de conhecimentos sobre o tema para a comparação dos resultados encontrados. Ressalta-se a carência de instrumentos que possam avaliar, sistematicamente, os egressos do programa, que possam nortear e facilitar a coleta de informações. Além disso, a dificuldade de contato com os egressos das primeiras turmas.

Assim, sugere-se o desenvolvimento de novos estudos que evidenciem cada vez mais as repercussões do programa para os alunos de graduação, auxiliando no fortalecimento do programa em todo o país.

\section{Contribuições das autoras}

Lopes TF realizou coleta de dados, análise dos resultados, tratamento estatístico e discussão dos dados. Da Silva BV, Vaz SS, Pereira JM realizaram coleta de dados e interpretação dos dados. Carvalho LS realizou interpretação dos dados e tratamento estatístico. Carvalho REFL orientou a pesquisa e análise dos dados.

\section{Conflitos de interesses}

Nenhum conflito financeiro, legal ou político envolvendo terceiros (governo, empresas e fundações privadas, etc.) foi declarado para nenhum aspecto do trabalho submetido (incluindo, mas não se limitando a subvenções e financiamentos, participação em conselho consultivo, desenho de estudo, preparação de manuscrito, análise estatística, etc.). 


\section{Referências}

1. Torina HF, Almeida LO, Paula JS. História do Programa de Educação Tutoria da FMRP-USP. Medicina. 2016;49(4):374-380. doi: 10.11606/issn.2176-7262.v49i4p374-380

2. Silva GNFL, Barbosa DS, Tsutsumi KP, Faria AF. Ferramenta de análise estratégica aplicada ao planejamento do Programa de Educação Tutorial (PET). Rev Lat-Am Inov Eng Prod. 2017;5(8):7797. doi: $10.5380 /$ relainep.v5i8.55809

3. Tiepolo LM, Denardin VF, Oliveira PSS, Onofre EV, Cardoso ER, Dias E et al. Conexão de Saberes: a experiência interdisciplinar do Programa de Educação Tutorial Comunidades do Campo da UFPR. Revista Extensão em foco. 2017;13(1):1-14. doi: 10.5380/ ef.vlil3.49498

4. Oliveira MSB, Jurado SR, Bassler TC, Moreira AS, Silva AV, Furlan MCR et al. Contribuições da educação tutorial para a formação do enfermeiro: uma reflexão teórica. Nursing. 2019;22(259):34523456. doi: 10.36489/nursing.2019v22i259p3452-3456

5. Campos CJG. Método de análise de conteúdo: ferramenta para a análise de dados qualitativos no campo da saúde. Rev Bras Enferm. 2004;57(5):611-4. doi: 10.1590/S003471672004000500019

6. Ministério da Saúde. Conselho Nacional de Saúde. Resolução $\mathrm{n}^{\circ} 466$, de 12 de dezembro de 2012. Aprova diretrizes e normas regulamentadoras de pesquisa envolvendo seres humanos [Internet]. 2012. [acesso em 2018 ago 30]. Disponível em: http://bvsms.saude.gov.br/bvs/saudelegis/cns/2013/ res0466_12_12_2012.html

7. Ministério da Educação. Secretária de Educação Superior. Programa Especial de Treinamento. Manual de orientações básicas PET [Internet]. 2008. [acesso em 2018 ago 28]. Disponível em: http://portal.mec.gov.br/sesu/arquivos/pdf/PETmanual.pdf.

8. Machado MH, Aguiar Filho W, Lacerda WF, Oliveira E, Lemos $\mathrm{W}$, Wermelinger $\mathrm{M}$ et al. Características gerais da enfermagem: o perfil sociodemográfico. Enferm. Foco. 2015;6(1/4):11-17. doi: 10.21675/2357-707X.2016.v7.nESP.686

9. Souza RM, Gomes Junior SR. Programa de Educação Tutorial: Avanços na formação em física no Rio Grande do Norte. Rev Bras Ensino Fís. 2015;37(1):1501-1505. doi: 10.1590/S1806-

11173711577
10. Riva C, Schoeninger AK. Inserção dos egressos do curso de administração no mercado de trabalho. Unoesc \& Ciência - ACSA. 2015;6(1):107-114.

11. Neves DS, Malta SCL. Ensino, pesquisa e extensão: existem dificuldades docentes no ensino superior para esta integração. Revista do Plano Nacional de Formação de Professores da Educação Básica. 2014;2(1):2-12.

12. Ministério da Educação. Secretaria de Educação Superior. Programa de Educação Tutorial. Portaria №343. [Internet]. 2013. [acesso em 2018 set 02]. Disponível em: http://sigpet.mec.gov.br/ docs/Portaria_343_2013.pdf

13. Ministério da Educação. Conselho Nacional de Educação. Resolução CNE/CES N 3, de 7 de Novembro de 2001 [Internet]. 2001. [acesso em 2018 set 02]. Disponível em: http://portal.mec. gov.br/cne/arquivos/pdf/CES03.pdf

14. Barbosa ES, Chaves MJC, Fernandes SCA. Programa de educação tutorial da faculdade de enfermagem da Universidade do Rio Grande do Norte: vivências e significados na formação de uma cultura acadêmica. Rev Debates em Educação. 2017;9(17):154-176. doi: 10.28998/2175-6600.2017v9n17p154

15. Rosin SM, Gonçalves ACA, Hidalgo MM. Programa de educação tutorial: lutas e conquistas. Revista ComInG. 2017;2(1):70-79. doi: $\underline{10.5902 / 2448190424495}$

16. Figueiredo WPS, Moura NPR, Tanajura DM. Ações de pesquisa e extensão e atitudes científicas de estudantes da área da saúde. Arq Ciênc Saúde. 2015;23(1):47-51. doi: 10.17696/23183691.23.1.2016.197

17. Carvalho CR, Barros RO, Reis EP, Araújo LB, Sousa HMH. O programa de educação tutorial: uma abordagem interdisciplinar sobre suas práticas no campus universitário petrônio portela. Revista Extensão em Foco. 2017;1(14):13-31.

18. Cossi MS, Costa RRO, Medeiros SM, Menezes RMP. A capacidade para o trabalho da equipe de enfermagem inserida no ambiente hospitalar. Rev de Atenção à Saúde. 2015;13(43):68-72. doi: $10.13037 /$ rbcs.vol13n43.2676 